Florida International University FIU Digital Commons

9-7-1999

\title{
Negative affectivity and its impact on role conflict, role ambiguity, and job satisfaction
}

Amy Rachelle Cooper

Florida International University

DOI: $10.25148 /$ etd.FI14061506

Follow this and additional works at: https://digitalcommons.fiu.edu/etd

Part of the Psychology Commons

\section{Recommended Citation}

Cooper, Amy Rachelle, "Negative affectivity and its impact on role conflict, role ambiguity, and job satisfaction" (1999). FIU Electronic Theses and Dissertations. 2522.

https://digitalcommons.fiu.edu/etd/2522

This work is brought to you for free and open access by the University Graduate School at FIU Digital Commons. It has been accepted for inclusion in FIU Electronic Theses and Dissertations by an authorized administrator of FIU Digital Commons. For more information, please contact dcc@fiu.edu. 


\title{
FLORIDA INTERNATIONAL UNIVERSITY
}

Miami, Florida

\section{NEGATIVE AFFECTIVITY AND ITS IMPACT ON ROLE CONFLICT, ROLE AMBIGUITY, AND JOB SATISFACTION}

\author{
A thesis submitted in partial fulfillment of the \\ requirements for the degree of \\ MASTER OF SCIENCE
}

in

PSYCHOLOGY

by

Amy Rachelle Cooper

1999 
To: Dean Arthur W. Herriott

College of Arts and Sciences

This thesis, written by Amy Rachelle Cooper, and entitled Negative Affectivity and Its Impact on Role Conflict, Role Ambiguity, and Job Satisfaction, having been approved in respect to style and intellectual content, is referred to you for judgment.

We have read this thesis and recommend that it be approved.

Juan I. Sanchez

Scott Fraser

Chockalingam Viswesvaran, Major Professor

Date of Defense: September 7, 1999

The thesis of Amy Rachelle Cooper is approved.

Dean Arthur W. Herriott College of Arts and Sciences

Dean Richard L. Campbell Division of Graduate Studies

Florida International University, 1999 


\section{DEDICATION}

I dedicate this thesis to my family and friends. Thank you for all of your support and encouragement. I love you. 


\section{ACKNOWLEDGMENTS}

I wish to thank the members of my committee for their unyielding support and guidance. I would especially like to thank my major professor, Dr. Chockalingam Viswesvaran, for his patience, direction, and continuous instruction.

I would also like to thank the interlibrary loan staff for their help. I am especially grateful to Ana Arteaga and Jorge Munoz, for their diligent pursuit of much needed articles. 
ABSTRACT OF THE THESIS

\section{NEGATIVE AFFECTIVITY AND ITS IMPACT ON ROLE CONFLICT, ROLE AMBIGUITY, AND JOB SATISFACTION}

by

Amy Rachelle Cooper

Florida International University, 1999

Miami, Florida

Professor Chockalingam Viswesvaran, Major Professor

Four alternate (mediational, suppressor, moderator, and direct effects) models of the role of negative affectivity on the correlation between role conflict or role ambiguity with job satisfaction were investigated. The correlations reported in the literature were cumulated using the principles of psychometric meta-analyses (Hunter \& Schmidt, 1990) to test the models for the effect of negative affectivity on 1) the role conflict- job satisfaction relationship, and 2) the role ambiguity- job satisfaction relationship. Of the nine metaanalyses conducted, correlational data were found in support of all hypothesized direct effects models, most mediational models, but no moderator or suppressor models. 


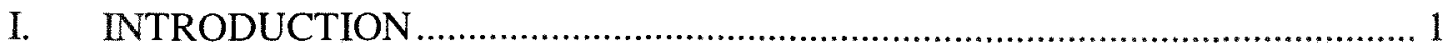

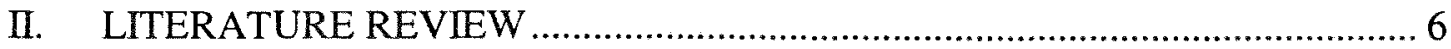

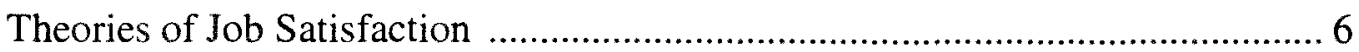

Empirical Research: Select Review .......................................................... 7

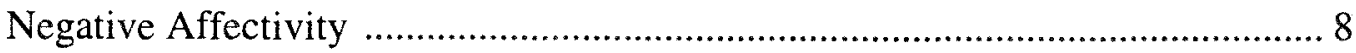

Models of Negative Affectivity .................................................................. 14

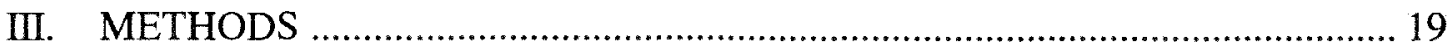

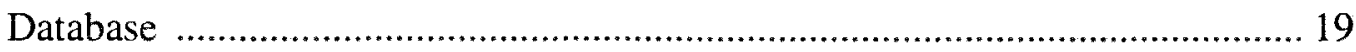

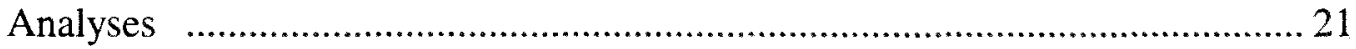

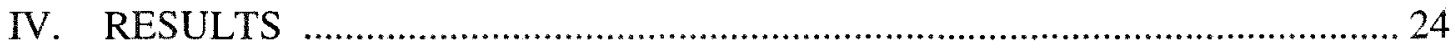

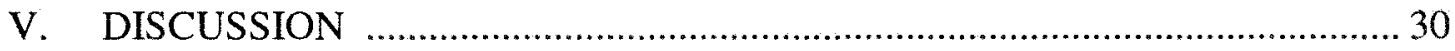

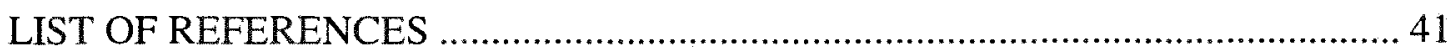

APPENDIX 


\section{LIST OF TABLES}

TABLE

PAGE

I. ROLE CONFLICT INSTRUMENTS _.......................................... 35

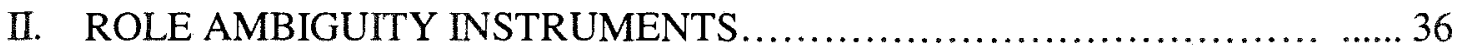

III. JOB SATISFACTION INSTRUMENTS .................................. 37

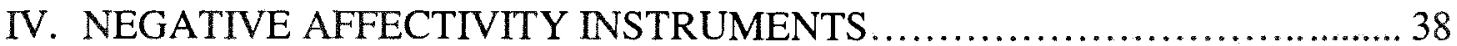

V. ARTIFACT DISTRIBUTIONS ............................................. 39

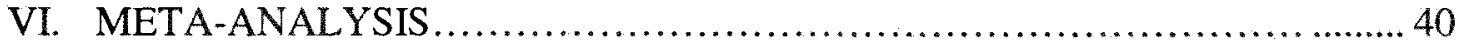




\section{CHAPTER I}

\section{Introduction}

For the past half century, much emphasis has been placed on role theory in the organizational sciences (King \& King, 1990). Researchers like Parsons, Merton, and Gross, Mason, and McEachern laid the foundation for role theory in the 1950s. The use of role concepts in understanding organizational behavior is due to the pioneering works of Kahn, Wolfe, Quinn, Snoek, and Rosenthal (1964). Kahn et al. developed a "role episode" model to explain how various roles influence the way an organization is run. The model indicates that there are certain conditions which must be met in order for a person to properly fulfill his/her role. The person needs to be aware of: 1) expectations, 2) what needs to be done to fulfill these expectations, and 3) how the actions will affect the self, other people, and the work environment at large. There are two central constructs within role theory: role conflict and role ambiguity (Abdalla, 1991; Kahn et al., 1964; King \& King, 1990).

Role conflict is "the degree of incompatibility of expectations associated with the role" (Singh, Goolsby, \& Rhoads, 1994, p. 559). Kahn et al. (1964) identify five forms of role conflict, including intra-sender conflict, inter-sender conflict, inter-role conflict, person-role conflict, and other complex forms like role overload (pp. 19-20). Intra-sender conflict occurs when one person (i.e., the employer) tells the employee to do two contradictory things. Inter-sender conflict arises when two different people are asking the employee to do two or more conflicting things. Inter-role conflict occurs when a person has opposing pressures from more than one role (i.e., work versus family pressures). 
Person-role conflict arises when the act of performing a task goes against one's moral values. Role overload happens when a person has too many responsibilities to perform in a given time period (Kahn et al., 1964).

Role ambiguity is defined by Kahn (1973) as " the discrepancy between the amount of information that a person has and the amount that he requires to perform his role adequately" (p. 9). Therefore, role ambiguity can sometimes occur because the employee has not been given enough knowledge to properly fulfill his role (Nhundu, 1992). Role ambiguity is determined, according to Sawyer (1992), by two things: distinct, intelligible "work goals," and the employee's working knowledge of how to achieve these goals. Kahn et al. (1964) identify both task ambiguity and ambiguity that is affected by socioemotional issues (p.94). Task ambiguity occurs when a person is unsure of his/her role (and how he/she is expected to perform) on the job. Ambiguity arising from socioemotional issues "manifests itself in a person's concern about his standing in the eyes of others and about the consequences of his actions for the attainment of his personal goals" (Kahn et al., 1964, p. 94).

There is an abundance of literature on role conflict and role ambiguity together. These two constructs, in specific, "have been given extraordinary empirical consideration" (Kemery, 1991). It might appear that conflict arises from ambiguity and vice versa. But, Kahn et al. (1964) are careful to indicate that these two constructs are separate entities. One construct is not dependent on the other, even if one might be a precursor to another in certain instances. 
The correlation between role conflict and role ambiguity has been examined with other variables in the research as well. Several empirical studies have examined the consequences of role conflict and role ambiguity on individual and organizational outcomes. In fact, two meta-analytic cumulations of this literature exist (Fisher \& Gitelson, 1983; Jackson \& Schuler, 1985). In general, role conflict and role ambiguity are negatively correlated with several important variables. One of these correlates is job satisfaction. Locke (1976, p.1342) explains the concept of job satisfaction as a "pleasurable emotional state resulting from the perception of one's job as fulfilling or allowing the fulfillment of one's important job values."

Earlier research investigating the relationship between role conflict or role ambiguity with job satisfaction has not taken into account the effects of negative affectivity. Negative affectivity is a pervasive tendency to respond with negative affect, which could inflate the correlation between role conflict or ambiguity with job satisfaction (Brief, Burke, George, Robinson, \& Webster, 1988; Chen \& Spector, 1991). In the last decade, researchers have attempted to quantify the inflation caused by negative affectivity (Chen \& Spector, 1991; Sanchez \& Viswesvaran, 1996). The variance inflation factor has been employed as an index of this overestimation of the role conflict(or ambiguity)- job satisfaction correlation.

For theoretical understanding as well as for practical applications, it is important to understand the process by which negative affectivity influences the correlation between role conflict or role ambiguity and job satisfaction. Such a research undertaking parallels the work of Viswesvaran, Sanchez, and Fisher (1999) who investigated alternate 
(mediational, suppressor, moderator, and direct effects) models of the role of social support on stressor-strain relationships.

In this thesis, I propose to investigate the alternate (mediational, suppressor, moderator, and direct effects) models of the role of negative affectivity on the correlation between role conflict or role ambiguity with job satisfaction. To test the alternate models, the correlation between negative affectivity, job satisfaction, and role conflict or role ambiguity is needed. I propose to cumulate the correlations reported in the literature using the principles of psychometric meta-analyses (Hunter \& Schmidt, 1990). A total of six meta-analyses across the four variables (negative affect, job satisfaction, role conflict, or role ambiguity) will be conducted. These six meta-analytically derived correlations will be used to test alternate models (Viswesvaran \& Ones, 1995). I will test alternate models for the effects of negative affectivity on 1) the role conflict- job satisfaction relationship, and 2) the role ambiguity- job satisfaction relationship.

The use of meta-analytically derived correlations to test path models has several advantages (Viswesvaran \& Ones, 1995). First, the increased sample size greatly mitigates the effects of sampling error and facilitates detection of moderator effects (Aiken \& West, 1993). Further, the use of heterogeneous samples is accomplished so that results are generalizable (Ganster, Fusilier, \& Mayes, 1986). However, this metaanalytic integration of the literature is limited to studies that employed all four (or three) measures: negative affectivity, job satisfaction, role conflict and/or role ambiguity. Studies that reported correlations between role conflict and job satisfaction, for example, without measuring negative affect, were not included. The reason for this strategy was to 
limit the analysis only to studies that had examined all variables included in the models hypothesized (cf. Hom, Caranikas-Walker, Prussia, \& Griffeth, 1992). Second, I also focus on global measures of ambiguity because very little research exists on the various facets of ambiguity (cf. Breaugh \& Colihan, 1994).

In this thesis, I first discuss the different theories of job satisfaction. Next, I review some studies that had examined the relationship between role conflict or role ambiguity and job satisfaction. Third, I discuss the literature on negative affectivity. Fourth, models of how negative affectivity could affect the relationships of interest are reviewed. Specific hypotheses that will be tested in this paper are stated. 


\section{CHAPTER II}

\section{Literature Review}

\section{Theories of Job Satisfaction}

Job satisfaction is an important variable in Industrial-Organizational Psychology. It has even been dubbed "morale" by some researchers (Kim, Price, Mueller, \& Watson, 1996). Job satisfaction is vital because it affects employees' attitudes toward work and the organization. Job satisfaction has been linked to a decrease in turnover and absenteeism (Beehr,1996).

Hackman and Oldham (1976) present a model which relates job satisfaction to motivation. Their Job Characteristics Model proposes that there are five "core job dimensions" of an employee's work which influence three "critical psychological states" and lead to many "personal and work outcomes." One of these outcomes is job satisfaction (Hackman \& Oldham, 1976).

Beehr (1996) indicates that there are three theories which can be applied to job satisfaction. They are discrepancy theory, social information processing, and the dispositional approach. The discrepancy theory indicates that job satisfaction is a result of what actually happens on the job as it relates to an individual's values, goals, or ideas about what should happen (Beehr, 1996). For instance, an employee might expect specific pay for accomplishing a certain amount of work. If he or she does not receive that pay after accomplishing the task, this might lead to job dissatisfaction because of the discrepancy between what he or she expected (needed) and what was ultimately given to him or her (Beehr, 1996). 
Social information processing is another theory, which states that one's

satisfaction on the job can be affected by the attitudes and comments of those around him or her (Beehr, 1996). For instance, if an employee is happy on the job, but his or her peers are not happy, then their negative attitudes might influence the employee's emotions or actions (Beehr, 1996).

The dispositional theory indicates that there are certain affective qualities of a person that will be there regardless of job environment. For instance, this theory indicates that some people are more prone to be happy in a job setting than others. The discrepancy theory implies that if an employee is not happy at a particular job (i.e. because it is not meeting his specific needs) then he should change jobs (Beehr, 1996). But, with the dipositional approach, if one is high in a negative disposition (negative affectivity), this person will not be happy in any job (Beehr, 1996).

\section{Empirical Research: Select Review}

Current research indicates that there are connections between role conflict, role ambiguity, and job satisfaction. Fulk and Wendler (1982) suggest that there is a relation between these three variables. According to Cordes \& Dougherty (1993), an employee will have higher job satisfaction if he/she understands the importance and outcome associated with properly (or improperly) fulfilling his or her role.

Butler and Ehrlich (1991) suggest that "attitudes and behaviors associated with one's position" may affect job satisfaction. And, Netemeyer, Johnston, and Burton (1990) say that both role conflict and ambiguity add to stress in the workplace, and negatively affect job satisfaction. 
Nhundu (1992) cites many examples of studies which indicate that role ambiguity negatively influences job satisfaction. Nhundu was careful to include, though, that the relationship between role ambiguity and job satisfaction is not always found to be significant. In addition, Szilagyi (1977) did not always find a significant inverse connection between role ambiguity and job satisfaction.

There have been meta-analyses of this correlation as well. For instance, Brown and Peterson (1993) conducted a meta-analysis, which indicated that role ambiguity and role conflict are directly related to job satisfaction. They found across 2641 individuals from 17 studies that the correlation between role conflict and job satisfaction was -.33 whereas the correlation between role ambiguity and job satisfaction was -..36 (across 2431 individuals of 15 samples). Abramis (1994) conducted a meta-analysis, which suggested that role ambiguity "is significantly and negatively related" to job satisfaction.

Of the meta-analyses conducted with these variables, there is one major discrepancy. It concerns whether or not a moderating variable might have an impact on the relationship between role conflict/ambiguity and job satisfaction. Fisher and Gitelson (1983) say that role conflict and role ambiguity are not affected by moderator variables. Jackson and Schuler (1985), on the other hand, indicate that moderator variables do influence role conflict and role ambiguity.

\section{Negative Affectivity}

When investigating the correlation between role conflict, role ambiguity, and job satisfaction, researchers need to account for negative affectivity (NA) as well. Watson and Clark (1984) define NA as a fixed characteristic that "reflects pervasive individual 
differences in negative emotionality and self-concept" (p. 465). One who is high in NA might have "subjective feelings of nervousness, tension, and worry" (Watson \& Clark, 1984, p. 465).

Negative affectivity is considered a "dispositional variable," which people introduce into their place of work (Kim et al., 1996). Clark and Isen (1982) indicate that affective disposition can impact one's mental state as well as his/her actions. Watson, Clark, and Tellegen (1988) suggest that someone who is high in NA will generally be angry and in a stressful state, whereas one who is low in NA will be more peaceful and calm. It is important to remember that people who are high in NA "are more likely, in any situation, to experience significant levels of distress than low NA individuals" (Brief et al., 1988).

Heinisch and Jex (1997) purport that NA can affect stressors and strains by serving as a moderating variable. What this means is that "individuals may be more or less reactive to job-related stressors depending upon whether they are high or low on the trait of NA" (Heinisch \& Jex, 1997). In their study, Heinisch and Jex (1997) found that "NA moderated the relationship between these stressors and work-related depression for females but not for males." Kim et al. (1996) state that one who has a positive or negative disposition may give misleading answers about work environment or job opportunities. For instance, one "who is predisposed to experience pleasant emotional states may also falsely report low stress and strong social support" (Kim et al., 1996). Negative affectivity has been related to job satisfaction in various studies. Agho, Mueller, and Price (1993) indicate that people who are high in NA are more prone to 
experience job dissatisfaction than those who are high in positive affectivity. In their study, Brief et al. (1988) partialled out NA from the "relationships between negative stress and distress or satisfaction." They found that when NA was "controlled for," the correlations between stress and strain relationships (which were strong when NA was included) were close to zero. They argue that if NA were controlled for in other studies, the correlations might be much "weaker" (Brief et al., 1988). Brief et al. (1988) cite the meta-analysis by Jackson and Schuler (1985) as a study which might have had different results if these principles were applied.

Several empirical studies have looked at role conflict, role ambiguity, job satisfaction, and NA. Few have interrelated all of these variables. Most research has looked at distinctive relationships amongst these variables. Of those studies which have related all four variables, there have been some interesting findings.

Kim et al. (1996) studied the "career intent" of doctors in a military hospital. They defined career intent as " the extent to which an employee plans to spend his or her life working within the military" (Kim et al., 1996). In their research, Kim et al. (1996) use a model developed by Price and Mueller, which is based on the expectancy theory. The expectancy theory, initially proposed by Vroom (1964) with regard to businesses, implies that workers come to the job with certain beliefs. If the organization satisfies these expectations, then the worker will probably continue to work for the organization (Kim et al., 1996). Kim et al. (1996) use the Price-Mueller model and include "structural and environmental variables" to determine whether employees will continue to work for the organization. One of those three variables is job satisfaction (Kim et al., 1996). 
The model looks at a total of 19 variables, all of which fall within four categories (Kim et al., 1996). The categories are "endogenous variables" (like job satisfaction), "environmental variables," "individual variables" (like negative affectivity), and "structural variables" (including job stressors like role conflict/ambiguity). I have chosen to only mention those specific variables which apply to the proposal at hand. For a more descriptive view of the model, please see Kim et al. (1996).

In their research, Kim et al. (1996) did not find role conflict or ambiguity to "be highly important... in their impact... on satisfaction." They claim that this is due to "extensive controls" that they placed on the job-stress variables (Kim et al., 1996). They recommend that similar controls be used in future studies so as to determine the accurate impact of these variables. They are implying, therefore, that the heavy importance of these variables, as indicated by previous research, is misleading because of lack of proper controls when measuring (Kim et al., 1996). They also found that negative affectivity did not have as important an affect on job satisfaction as did positive affectivity (Kim et al., 1996).

In a study conducted a few years prior to the Kim et al. (1996) study, Agho, Mueller, and Price (1993) also used the Price-Mueller model while examining these and other variables. They also revised the model to adapt to current literature. They studied 405 employees of a medical center run by the Veterans Administration. They measured satisfaction by using an adapted version of a scale promoted by Brayfield and Rothe in 1951 (Agho et al., 1993). 
Their results showed "that employees are less satisfied with their jobs when they have alternate jobs for which they are qualified, do not have the information needed to perform their tasks adequately, and receive incompatible requests from their superiors" (Agho et al., 1993). This indicates that role conflict and role ambiguity do have an impact on job satisfaction, as most research has implied. Agho et al. also found that those higher in NA had a more negative attitude about their jobs than those lower in NA. They do suggest, though, that more research needs to be done with regard to disposition and how it affects job satisfaction (Agho et al., 1993). This is because "while the hypothesized positive effect of positive affectivity on satisfaction was supported, the hypothesized negative effect of negative affectivity was not supported in this study" (Agho et al,, 1993).

Chen and Spector (1991) attempted to replicate the earlier findings of the 1988 Brief et al. study. They interviewed 400 subjects to see if NA had an affect on the relation between "self-reported" stressors and strains (Chen \& Spector, 1991). They found "significant correlations" between stressors and strains. NA "was found to account for a large proportion of shared variance between stressors and physical strains... [but] did not account for much of the variance shared by stressors and affective strains" (Chen \& Spector, 1991). An example of an affective strain would be job satisfaction, while an example of a physical strain would be "physical symptoms and doctor visits" (Chen \& Spector, 1991). This differentiation is important because it helps to clarify why there are conflicting results in the literature. As Chen and Spector (1991) noted, "although NA did 
not explain the major portion of relations between most stressors and strains, it may explain a small amount of the variance in these reports."

According to Kemery (1991), "when work takes on a negative connotation, creating an aversive context for an employee, psychological symptoms such as decreased job satisfaction, lower job involvement, and less organizational commitment could result, particularly in situations where behavioral withdrawal is constrained by situational and/or personal factors." Kemery proposed that NA influences what happens in an organization because it affects how much "role stress" an employee encounters. The higher the NA, the more stress he or she will have (Kemery, 1991).

Kemery (1991) used archival and questionnaire data for 101 subjects to test his hypotheses. He found that NA affected both role conflict and ambiguity. Kemery added that "dispositional affect accounted for variance not captured by role conflict or role ambiguity in job satisfaction and organizational commitment."

Nonetheless, no matter the specific variables examined in the study, each has been limited in some way. For instance, many of the studies are small in sample size. Kim et al. (1996) state, in the data analysis section, that "because of the relatively small sample size, data were analyzed by ordinary least squares (OLS) regression analysis rather than covariance structure analysis (LISREL)." Their sample consisted of 244 doctors. Agho et al. (1993), whose sample consisted of 405 subjects, were able to analyze using LISREL. But, Kemery indicated that this work could be criticized because of the small sample size, as there was "limited ability to detect modest effect sizes" (1991). 
Negative affectivity can have several effects on the correlations. Negative affectivity can serve as a mediator, moderator, and/or have a direct effect on the variables. Below is a review of the various models and an explanation of how they can be applied to NA as it correlates to role conflict, role ambiguity, and job satisfaction. Please note the potential for multiple effects.

\section{Models of Negative Affectivity}

\section{Direct Effects Models}

The direct effects model (Viswesvaran et al., 1999) suggests that NA acts on job satisfaction independent of role conflict or role ambiguity. Based on the studies by Agho et al. (1993), Watson, et al. (1988), and Brief at al. (1988), the direct effects model, as applied here, states that NA will decrease job satisfaction independent of the degree of role conflict or role ambiguity.

Hypothesis 1: NA will be negatively correlated with job satisfaction.

Negative affectivity can also have a direct effect on role conflict or role ambiguity (Viswesvaran et al., 1999). Based on the study by Brief et al. (1988), the direct effects model can be stated as:

Hypothesis 2a: NA will be positively correlated with role conflict.

Hypothesis $2 \mathrm{~b}$ : NA will be positively correlated with role ambiguity. 


\section{Mediational Models}

Mediator effects models. Test of mediational models with correlational data is

limited. While it is possible to disconfirm mediational models with correlational data, confirmation requires longitudinal and experimental data (Viswesvaran et al., 1999). The objective here is only to test the plausibility of the models. There are two aspects of this model: the partial mediation model and the full mediation model (Viswesvaran et al., 1999). "Evidence supports a full mediation model if the partial correlation... [between two variables] drops to zero" after one partials-out for the mediator.

Based on the study by Brief et al. (1988), the full mediation model can be applied to suggest that NA will mediate the relationship between role conflict (and/or role ambiguity) and job satisfaction. This conceptualization implies that role conflict or role ambiguity affects job satisfaction by influencing the negative affect experienced by individuals. Individual differences in negative affect are taken as a reflection of individual differences experienced in role conflict or role ambiguity. (See below for a mediational model based on a dispositional view of negative affectivity.)

Hypothesis 3a: NA will be a full mediator of the relationship between role conflict and job satisfaction.

Hypothesis $3 \mathrm{~b}$ : NA will be a full mediator of the relationship between role ambiguity and job satisfaction.

As mentioned above, the other type of mediator effects model is the partial mediation model. When there is a drop in the partial correlation between two variables, a partial correlation model is supported (Viswesvaran et al., 1999). Based on the study by 
Brief et al. (1988), the partial mediation model can be applied to suggest that NA will serve as a partial mediator in the relationship between role conflict (and/or role ambiguity) and job satisfaction.

Hypothesis 4a: NA will be a partial mediator in the relationship between role conflict and job satisfaction.

Hypothesis 4b: NA will be a partial mediator in the relationship between role ambiguity and job satisfaction.

There is an additional conceptualization of the mediator effects model as Beehr and McGrath (1992) indicate, with their example of social support and stress, that stressors could function as a mediator. Following their design, and based on the studies by Abramis (1994) and Brown and Peterson (1993), it might be possible to use the full mediation model to suggest that role conflict (or role ambiguity) will serve as a mediator in the correlation between NA and job satisfaction.

Researchers have conceptualized negative affectivity as a dispositional variable and have linked it to the emotional stability factor of the Big Five Factor Model of Personality (George, 1996). To the extent that negative affectivity is a personality characteristic, it becomes a defining characteristic of an individual. In such an event, it is more likely to be an antecedent to job satisfaction with role conflict or role ambiguity as the mediator (rather than negative affectivity being a mediator of the role conflict/ambiguity- job satisfaction relationship). Thus, individuals high on negative affectivity will interpret organizational events as more conflictual or in ambiguous terms. 
The effect of negative affectivity on job satisfaction is due to individuals high on negative affectivity perceiving more ambiguity and conflict.

Hypothesis 5a: Role conflict will serve as a full mediator of the relationship between NA and job satisfaction.

Hypothesis 5b: Role ambiguity will serve as a full mediator of the relationship between NA and job satisfaction.

Based on the studies by Abramis (1994) and Brown and Peterson (1993), it is also possible that the partial mediation model might be used to suggest that role conflict (and/or role ambiguity) will serve as a partial mediator in the relationship between NA and job satisfaction.

Hypothesis 6a: Role conflict will be a partial mediator of the relationship between NA and job satisfaction.

Hypothesis 6b: Role ambiguity will be a partial mediator of the relationship between NA and job satisfaction.

Suppressor effects model. The suppressor effects model suggests that NA acts on role conflict (or role ambiguity) to increase the partial correlation between these variables and job satisfaction (Viswesvaran et al., 1999). In this model, negative affectivity suppresses the invalid variance in the measure of one of the two variables correlated. The suppressor effects model can be stated as:

Hypothesis 7a: NA will be a suppressor for the relationship between role conflict and job satisfaction.

Hypothesis 7b: NA will be a suppressor for the relationship between role 
ambiguity and job satisfaction.

Note, however, that for a suppression effect to occur, the suppressor variable (i.e., NA) should correlate with one of the variables correlated, but not both. But previous meta-analytic cumulation suggests that NA correlates with both job satisfaction and role conflict (or role ambiguity). Further, NA has negative correlations with both variables (job satisfaction and role conflict or role ambiguity). Thus, it is highly unlikely that NA will be a suppressor of the relationship between role conflict (or role ambiguity) and job satisfaction. This is consistent with the findings of Viswesvaran et al. (1999) that social support is not a suppressor of the stressor-strain relationship, in general. I include these suppressor hypotheses here only for a comprehensive coverage of testing all potential models.

\section{Moderator Effects Model}

The moderator effects model suggests that NA interacts with role conflict or role ambiguity to affect job satisfaction (Viswesvaran et al., 1999). Based on the studies by Heinisch and Jex (1997), Kemery (1991), and Jackson and Schuler (1985), the moderator effects model can be applied to propose that as NA increases, the negative correlation between role conflict (and/or role ambiguity) and job satisfaction becomes stronger.

Hypothesis 8a: NA will be a moderator of the relationship between role conflict and job satisfaction.

Hypothesis $8 \mathrm{~b}$ : NA will be a moderator of the relationship between role ambiguity and job satisfaction. 


\section{CHAPTER III}

\section{Methods}

\section{Database}

A computerized search was done on PsycInfo to identify articles to be used for the meta-analysis. One hundred twenty-four articles were found containing any of the following keywords: role conflict, role ambiguity, job satisfaction, negative affectivity, neuroticism, and trait anxiety. Only those articles which contained three (or four) of the variables (as described earlier) were kept for this study. Additionally, I hand-searched the following eleven journals for relevant articles: Work and Stress, Journal of Management, Journal of Vocational Behavior, Journal of Organizational Behavior, Journal of Applied Psychology, Personnel Psychology, Academy of Management Journal, Organizational Behavior and Human Decision Processes, Journal of Occupational Health Psychology, Psychological Reports, and Human Relations. I "snowballed" the references from any applicable article to identify other potential articles. I did not actively seek conference articles or chapters from books. However, I included any that were identified in my literature search.

A total of 42 articles were tagged as appropriate for the meta-analysis. The measures of role conflict that were included in the database, along with the frequencies of their use, are listed in Table 1. Similarly, the instruments used to measure role ambiguity, job satisfaction, and negative affectivity are delineated in Tables 2,3, and 4, respectively. A complete list of citations of all articles used in the meta-analysis is provided in the Appendix. 
There were certain inclusion criteria used when designating articles: 1) The study had to use employees in an actual organization. 2) There had to be at least three or four of the measures (NA, job satisfaction, role conflict and/or role ambiguity) used in the study. 3) If the study was a longitudinal study, I took the cross section correlations at all times. I also took the correlates where NA and role conflict/ambiguity were measured at time one and job satisfaction at time two. 4) Wherever possible, I converted any statistics to correlations.

I coded the correlations, the corresponding sample sizes, and the reliabilities of the measures. I also coded the $\Delta \mathrm{R}^{2}$ when NA was added to the regression of role conflict (or role ambiguity) on job satisfaction. I also specifically coded the measures of role conflict, role ambiguity, NA, and job satisfaction, used in each study.

One study, in particular, stood-out in sample size from the other studies. This was the study by Williams and Cooper (1998). Every correlation coded for this study had a sample size of 8,503 . Since such a large sample size from a single study might skew the results, a decision was made to run the appropriate meta-analyses both with and without the data from the Williams and Cooper (1998) study. Since this article contained correlations for the variables role conflict, job satisfaction, and negative affectivity, it was determined that three extra meta-analyses would be conducted, in addition to the original six meta-analyses. There would be six all-inclusive meta-analyses and three separate meta-analyses, excluding the data from the Williams and Cooper (1998) study. 


\section{Analyses}

The first step in the analyses was to code the located articles. Nine meta-analyses were conducted. The first six included the following correlations from every article in the data set: 1) role conflict and job satisfaction, 2) role conflict and NA, 3) role conflict and role ambiguity, 4) role ambiguity and job satisfaction, 5) role ambiguity and NA, and 6) NA and job satisfaction. The last three meta-analyses were based on all of the studies in the data set excluding the data from the Williams and Cooper (1998) study, as explained above. These three meta-analyses were conducted to estimate the correlation between: 7) role conflict and job satisfaction, 8) role conflict and NA, and 9) NA and job satisfaction. The mean observed correlations were corrected for unreliability in the two measures correlated. Artifact distribution based meta-analysis (Hunter \& Schmidt, 1990) was used. Coefficient alphas and test-retest reliabilities were included in the artifact distribution. The interactive procedures with the refinements suggested in Schmidt et al. (1993) were employed.

The nine meta-analytically determined correlations were used to test the different models hypothesized. To test the direct effects models (hypotheses 1, 2a, 2b), the appropriate zero-order correlations and their $95 \%$ credibility intervals were examined.

For example, to test hypothesis 1, the true score correlation between NA and job satisfaction was examined. A substantial negative correlation where the $95 \%$ credibility interval excludes zero, was taken as evidence supporting the hypothesis.

To test the mediational models (hypotheses $3 a, 3 b, 4 a, 4 b$ ) where NA mediates the relationship between role conflict or role ambiguity and job satisfaction, I computed the 
partial correlation between role conflict or role ambiguity and job satisfaction with NA partialled out. Two partial correlations were computed. The variance reduction factor (VRF) was computed as follows. The difference between the square of the zero-order and partial correlations was divided by the square of the zero-order correlation. If the VRF is $100 \%$ (i.e., the partial correlation drops to zero), there is evidence for a full mediational model. If the partial correlation drops, but not to zero, the VRF will be less than $100 \%$. Such an outcome is indicative of support for the partial mediation model.

To test the mediational models (hypotheses 5a, 5b, 6a, 6b) where role conflict (or role ambiguity) mediates the NA- job satisfaction relationship, role conflict (or role ambiguity) was partialled out of the NA-job satisfaction correlation. Again, the two partial correlations were compared with the corresponding zero-order correlations. The variance reduction factor was examined to test partial and full mediational models.

To test the suppressor effects (hypotheses $7 \mathrm{a}, 7 \mathrm{~b}$ ), again the partial correlation between role conflict (or role ambiguity) and job satisfaction with NA partialled out was compared to the zero-order correlation between role conflict (or role ambiguity) and job satisfaction. An increase in the magnitude of the partial correlation compared to the zeroorder correlation constitutes evidence supportive of the suppressor effects model.

To test the moderator effects model (hypotheses $8 \mathrm{a}, 8 \mathrm{~b}$ ), the incremental $\mathrm{R}^{2}$ when NA was added to the regression of role conflict (or role ambiguity) on job satisfaction, is averaged across the studies. Note that this averaging is a preliminary and rough attempt to quantify the moderator effect. Several unresolved methodological issues exist 
(Viswesvaran et al., 1999), and the average $\Delta \mathrm{R}^{2}$ should be construed only as a tentative index of the moderation effect across the existing studies. 


\section{CHAPTER IV}

\section{Results}

Table 5 summarizes the artifact distributions of the variables used. The mean square roots of reliability varied from .8805 to .9077 . This table provides seven artifact distributions. This is because the data from the Williams \& Cooper (1998) study were both included and excluded when the mean square root of reliability was taken for these variables, as previously explained. Regardless, all of the artifact distributions were high enough, in value, to be deemed appropriate for use in the study.

The results of the nine meta-analyses are delineated in Table 6 . The number of studies used in each meta-analysis varied from 27 to 82 . The total sample size in each meta-analysis varied from 6,613 to 43,625 . The sample size weighted mean observed correlations varied from -.30 to .33 for the respective correlations. The RC-JS correlation was extremely low, at -.10 . When the Williams and Cooper (1998) study was excluded from the database, the RC-JS correlation was much stronger, at -.30. The strongest positive correlation (.33) was attributed to the RC-RA correlation.

Hypothesis 1 states: NA will be negatively correlated with job satisfaction. The true score correlation between NA and JS was used to test this hypothesis. There is enough evidence to indicate that NA is negatively correlated with JS, since the true score correlation $(\rho)$ is -.34 for the NA-JS correlation. The $95 \%$ credibility intervals ranged from -.13 to -.55 . Since the credibility intervals did not include zero, I conclude that there is a significant direct effect. Thus, Hypothesis 1 is supported. Hypothesis 1 is also 
supported for the NA-JS correlation which excludes the Williams \& Cooper (1998) study. The true score correlation there is -.30 .

Hypotheses $2 \mathrm{a}$ and $2 \mathrm{~b}$ also reflect the direct effects model. Hypothesis 2a states: NA will be positively correlated with role conflict. This hypothesis is supported both with and without the Williams and Cooper (1998) data. The true score correlation is .33 for the all-inclusive RC-NA correlation, while $\rho$ is .29 for the RC-NA correlation which excludes the data from the Williams \& Cooper (1998) study. The $95 \%$ credibility intervals did not include zero. Hypothesis $2 \mathrm{~b}$ states: NA will be positively correlated with role ambiguity. This hypothesis is supported because $\rho$ is .27 for the RA-NA correlation. The $95 \%$ credibility intervals did not include zero either. This suggests a significant relationship as hypothesized.

Hypotheses $3 \mathrm{a}$ to $6 \mathrm{~b}$ reflect mediational models. Hypothesis $3 \mathrm{a}$ states: NA will be a full mediator of the relationship between role conflict and job satisfaction. First, the complete data set was used to test the hypothesis. Then, the same test was run, while excluding the data from the Williams and Cooper (1998) study. Using the estimated true score correlations of -.34 between NA and JS, .33 between RC and NA, and -.12 between RC and JS, the partial correlation between RC and JS was computed, with NA partialled out. That partial correlation was -.01 . The full mediation model is supported when the partial correlation lowers to zero, after partialling out for the mediator (Viswesvaran et al., 1999). The variance reduction factor here is $99.46 \%$. There is evidence, therefore, to indicate that NA is a full mediator of the relationship between $\mathrm{RC}$ and JS, when dealing with the full data set. After excluding the Williams and Cooper 
(1998) study, $\rho$ was -.30 for NA and JS, .29 for RC and NA, and -.37 for RC and JS. The partial correlation between RC and JS was computed, with NA partialled out. This partial correlation was -.31 . Because the partial correlation $(-.31)$ was comparable in magnitude and in sign to the zero-order correlation of -.37 , the full mediation model was not supported with this data, which excluded the Williams \& Cooper (1998) study.

Hypothesis $3 b$ states: NA will be a full mediator of the relationship between RA and JS. Using the estimated true correlations of .27 between RA and NA, -.34 between NA and JS, and -.35 between RA and JS, the partial correlation between RA and JS was computed, with NA partialled out. The partial correlation here was -.29 . Because the partial correlation (-.29) was comparable in magnitude and in sign to the zero-order correlation of -.35 , there is not enough evidence to support the full mediation model here.

Hypothesis 4a states: NA will be a partial mediator in the relationship between RC and JS. Regarding the complete data set, this hypothesis was not supported. This is because evidence supporting a full mediation model was delineated in Hypothesis $3 \mathrm{a}$. However, the full mediation model was not supported for the data set which excluded the Williams and Cooper (1998) study. With that data set, there is evidence of partial mediation. The variance reduction factor is only $29.80 \%$. This suggests that NA serves as a slight partial mediator in the relationship between RC and JS, when the data from the Williams and Cooper (1998) study are excluded.

Hypothesis 4b states: NA will be a partial mediator in the relationship between RA and JS. In this instance, the variance reduction factor is $33.65 \%$, indicating that NA serves as a slight partial mediator in the relationship between RA and JS. 
Hypothesis 5a states: RC will serve as a full mediator of the relationship between NA and JS. Regarding the all-inclusive data set, the true score correlation ( $\rho$ ) was -.12 between RC and JS, .33 between NA and $\mathrm{RC}_{r}$, and -.34 between NA and JS. The partial correlation between NA and JS was computed, with RC partialled out. This partial correlation was -.32 . Since the partial correlation was similar in both magnitude and sign to the zero-order correlation, there is not enough evidence to support the full mediation model here. When the data from the Williams and Cooper (1998) study is excluded, $\rho$ is -.37 between RC and JS, .29 between RC and NA, and - .30 between NA and JS. The partial correlation here is -.22 , when $\mathrm{RC}$ is partialled out from the correlation between NA and JS. Again, since the partial correlation has not dropped to zero, and since it is similar in both magnitude and sign to the zero-order correlation (-.30), there is not enough evidence to support the full mediation model here.

Hypothesis 5b states: RA will serve as a full mediator of the relationship between NA and JS. The true score correlation is -.35 between RA and JS, .27 between NA and RA, and -.34 between NA and JS. The partial correlation is -.27 , when partialling out RA from the correlation between NA and JS. Since -.27 is similar in magnitude and in sign to the zero-order correlation $(-.34)$, there is not enough evidence to support the full mediation model here.

Hypothesis 6a states: $\mathrm{RC}$ will be a partial mediator of the relationship between NA and JS. The variance reduction factor is $11.12 \%$ for the data set which is allinclusive. This indicates that $\mathrm{RC}$ serves as a very slight mediator here. The variance reduction factor for the data set which excludes the Williams and Cooper (1998) study, 
however, is much higher, at $47.82 \%$. This indicates that there is stronger support for RC serving as a partial mediator when the Williams \& Cooper (1998) data are excluded.

Hypothesis $6 \mathrm{~b}$ states: RA will be a partial mediator of the relationship between NA and JS. The variance reduction factor here is $35.91 \%$. This indicates that RA serves as a slight mediator in the relationship between NA and JS.

Hypotheses 7a and 7b posit a suppressor model. Hypothesis 7a states: NA will be a suppressor for the relationship between RC and JS. There is not enough evidence to support the suppressor model here, neither with the all-inclusive data set nor with the data set which excludes the Williams \& Cooper (1998) study. This is because, in both instances, the absolute value of the square of the true score correlation is bigger than the absolute value of the square of the respective partial correlations. With the all-inclusive data set, $\rho$ was -.12 and the partial correlation was -.01 . With the data set excluding the Williams and Cooper (1998) study, $\rho$ was -.37 and the partial correlation was -.31 .

Hypothesis 7b states: NA will be a suppressor for the relationship between RA and JS. The absolute value of the square of the true correlation is bigger than the absolute value of the square of the partial correlation. Here, $\rho$ is -.35 and the partial correlation is .29. Therefore, there is not enough evidence to support the suppressor model here.

Hypotheses $8 \mathrm{a}$ and $8 \mathrm{~b}$ were not tested. Hypothesis $8 \mathrm{a}$ states: NA will be a moderator of the relationship between RC and JS. Hypothesis $8 b$ states: NA will be a moderator of the relationship between RA and JS. These hypotheses could not be tested because there were not enough incremental $R^{2} s$ in the data set. There were very few estimates of incremental $R^{2}$. Very few studies reported the increment in $R^{2}$ when a 
product of RA or RC with NA was added to a regression of RA or RC and NA on JS.

Thus, I was unable to test the moderator effects model. 


\section{CHAPTER V}

\section{Discussion}

Role theory is important in the organizational sciences (King \& King, 1990). Role conflict and role ambiguity are both important constructs within role theory (Abdalla, 1991; Kahn et al., 1964; King \& King, 1990). One of the variables that role conflict and role ambiguity have been negatively correlated with is job satisfaction (Abramis, 1994; Brown \& Peterson, 1993). However, researchers have argued about the role that negative affectivity plays in the role conflict-(or ambiguity)- job satisfaction relationship (Brief et al., 1988; Chen \& Spector, 1991). This study meta-analytically looked at negative affectivity with these three variables (role conflict and/or role ambiguity and job satisfaction). The purpose of this study was to advance the theoretical understanding of the role that NA has on these variables and on their respective relationships.

Nine meta-analyses were conducted. Of these nine tests, correlational data was found in support of all hypothesized direct effect models. The hypotheses were similarly supported by both the all-inclusive data set as well as the data set which excluded the Williams and Cooper (1998) study. Specifically, NA was shown to be negatively correlated with job satisfaction. Also, NA was shown to be positively correlated with both role conflict and role ambiguity.

Regarding the mediational models, there was support for NA as a full mediator of the relationship between role conflict and job satisfaction, only when running the allinclusive data set. When testing the same hypothesis with the data set excluding the Williams and Cooper (1998) study, there was not enough evidence to support the full 
mediation model; however, the partial mediation model was supported here. A possible reason for this discrepancy is because of the large sample size from the Williams and Cooper (1998) study. They had 8,503 subjects. In addition, while their correlations were generally in sync with the correlations found in other studies, their correlation of -.04 for $\mathrm{RC}$ and JS was extremely and comparatively weak. (Two measures of RC were included in their study, and were, therefore, included in the meta-analysis.) All of the other studies had comparatively much smaller sample sizes, and much stronger correlations between $\mathrm{RC}$ and JS. This is reflected as seen in Table 6. When the Williams and Cooper (1998) study is included, $\rho$ is -.12 . The true score correlation increases in magnitude to $-.37$ when the data from the Williams and Cooper (1998) study is excluded. Due to the drastic effects that this one study had on the data set, it was necessary to test each relevant model with and without the data from the Williams and Cooper (1998) study.

Please note that the purpose, here, was only to test the plausibility of the models. This is because, while it is possible to disconfirm mediational models with correlational data, confirmation requires longitudinal and experimental data (Viswesvaran et al., 1999). There was slight support for NA as a partial mediator between role ambiguity and job satisfaction. There was also only tentative support for both role conflict and/or role ambiguity as respective partial mediators between negative affectivity and job satisfaction. The one exception to the above statement is when the data set excluding the Williams and Cooper (1998) study was used to test for RC as a partial mediator for the NA- JS relationship. Here, there was relatively strong support for RC as a partial mediator, as the variance reduction factor was $47.82 \%$. Compare this result to the 
variance reduction factor for the same model when the all-inclusive data set was used. Here, the variance reduction factor is only $11.12 \%$. This is the smallest of all of the variance reduction factor percentages in our meta-analysis. Rationale for this major discrepancy is similar to the reasoning stated above. The Williams and Cooper (1998) study had a very large sample size and a correlation for the RC-JS relationship which was much weaker than any of the other RC-JS correlations in the other respective studies. That is why there is such a difference in the results when the Williams and Cooper (1998) study is either included or excluded from out data set.

A comparison of the variance reduction factors suggest more support for role conflict or role ambiguity as mediator of the negative affectivity-job satisfaction relationship than for a model where negative affectivity is a mediator of the role conflict (or role ambiguity)- job satisfaction relationship. This pattern of finding implies that while individual differences in negative affectivity are shaped by situational and dispositional factors, negative affectivity is more dispositional in nature. This is also consistent with the literature linking negative affectivity to the personality dimensia of emotional stability (George, 1996). There was no support for the suppressor effects model. And, there was not enough data to properly test the moderator effects model. This study provides many implications for science and practice. Through the use of meta-analysis, we are now more aware of the role of NA on the role conflict-(or role ambiguity)- job satisfaction relationship. The results in support of the mediation models (as depicted above), lends support to existing scientific research, which indicates that NA could inflate the correlation between role conflict or ambiguity with job satisfaction 
(Brief et al., 1988; Chen \& Spector, 1991). Also, the works of Abramis (1994) and Brown and Peterson (1993) are supported with the findings in support of RC and/or RA as respective partial mediators in the correlation between NA and job satisfaction. In addition, support in favor of the direct effects models indicate that NA has a direct effect on all three variables (role conflict, role ambiguity, and job satisfaction). This supports the respective works of Agho et al. (1993), Watson et al. (1988), and Brief at al. (1988).

From a practical standpoint, it seems that NA has an important impact on JS. It has already been illustrated, through meta-analysis (Abramis, 1994; Brown \& Peterson, 1993; Fisher \& Gitelson, 1983; Jackson \& Schuler, 1985), that role conflict and/or role ambiguity are directly and negatively correlated with job satisfaction. This study has shown that there is also a direct effect between NA and role conflict, role ambiguity, and job satisfaction. This could have serious implications in the workforce. One reason is because employers are continuously trying to increase job satisfaction. It might have been understood, from past research, that one way to increase job satisfaction is to decrease role conflict and/or role ambiguity. But, this meta-analysis indicates that NA has a direct, positive effect on role conflict and role ambiguity, respectively. The study also indicates that NA has a direct and negative effect on job satisfaction. In addition, while correlational data cannot prove a model to be true, there are definite implications that NA serves as a mediator to some degree in the role conflict (or ambiguity)- job satisfaction relationship. Since this is a dispositional characteristic, the employer must come up with new ways to increase job satisfaction and to handle role conflict/ambiguity issues. 
Industrial-Organizational Psychologists have studied the feasibility of various approaches to job design (e.g. Hackman \& Oldham, 1980). A guiding principle in job design efforts is to design the job so as to enhance satisfaction and motivation of employees. The results reported in this thesis suggest that the effects of job design on job satisfaction could be limited to the extent that individual dispositional differences in negative affectivity influence job satisfaction (both directly and as a mediator).

There were several limitations in this study. First of all, there were not enough incremental $\mathrm{R}^{2}$ s, so we were unable to test the moderator effects model. Other limitations preclude causal relationships. For example, most studies were cross-sectional, and very few were longitudinal. Other limitations focus on the generalizability of the results. Most of the subjects were from North America. Very few studies encompassed other countries. Also, potential moderators of the six bivariate relationships should be explored. In addition, there was no experimental manipulation. This means that only correlational information is available, as opposed to data indicating causation.

In summary, the results reported in this thesis shed light on some potential process mechanisms by which negative affectivity could play a role. Results indicate that negative affectivity is more dispositional in nature, which facilitates an integration of this literature with the more voluminous literature on the role of personality at work. Given the increasing emphasis on the role of dispositions in explaining workplace behaviors, more research is needed on the role of negative affectivity in the role episode model. 
TARLE I

\section{Bole Conflict Instruments}

SCALE

Rizzo, House, and Lirtzman's measure of

RC (1970)

Spector's measure of interpersonal conflict

(1987)

Spector et al.'s measure of interpersonal conflict (1988)

Nurse Stress Index

(Harris, Hingley, \& Cooper, 1988)

Nurse Stress Index (Harris, 1989)

Parasuraman \& Alutto's measure of RC

(1981)

Sources of Pressure in Your Job

Questionaire

(Cooper, Sloan, \& Williams, 1988)

Holahan and Gilbert's measure of RC

(1979)

House \& Rizzo's measure of RC (1972)

Caplan et al.'s measure of RC (1980)

Pressure Management Indicator

(Williams \& Cooper, 1998)

Bohen and Viveros-Long's measure of RC (1981)

Kopelman, Greenhaus, and Connelly's measure of RC (1983)
FREQUENCY

18

3

1

1

1

1

1

1

1

1

1

1

1 
TABLE II

\section{Role Ambiguity Instruments}

\begin{tabular}{lc}
\hline \multicolumn{1}{c}{ SCALE } & FREQUENCY \\
\hline Rizzo, House, and Lirtzman's measure of & 17 \\
RA (1970) & 2 \\
Beehr, Walsh, and Taber's measure of RA & \\
(1976) & 2 \\
Caplan et al.'s measure of RA (1980) & 1 \\
Gray-Toft \& Anderson's measure of RA & 1 \\
(1985) & 1 \\
Occupational Roles Questionaire & 1 \\
(Osipow \& Spokane, 1987) & \\
\hline
\end{tabular}




\section{Job Satisfaction Instruments}

\begin{tabular}{|c|c|}
\hline SCALE & FREQUENCY \\
\hline $\begin{array}{l}\text { Job Diagnostic Survey } \\
\text { (Hackman \& Oldham, 1975) }\end{array}$ & 5 \\
\hline $\begin{array}{l}\text { Job Satisfaction Scale } \\
\text { (Warr, Cook, \& Wall, 1979) }\end{array}$ & 5 \\
\hline $\begin{array}{l}\text { Michigan Organizational Assessment } \\
\text { Questionnaire } \\
\text { (Cammann et al., 1979) }\end{array}$ & 4 \\
\hline Brayfield \& Rothe Index (1951) & 3 \\
\hline Faces Scale (Kunin, 1955) & 3 \\
\hline $\begin{array}{l}\text { Facet Free Job Satisfactin Scale } \\
\text { (Quinn \& Staines, 1979) }\end{array}$ & 3 \\
\hline Caplan et al. measure of JS (1980) & 2 \\
\hline $\begin{array}{l}\text { Job Descriptive Index } \\
\text { (Smith, Kendall, \& Hulin, 1969) }\end{array}$ & 2 \\
\hline $\begin{array}{l}\text { Nurse Stress Index } \\
\text { (Harris, Hingley, \& Cooper, 1988) }\end{array}$ & 1 \\
\hline Hoppock measure of JS (1935) & 1 \\
\hline $\begin{array}{l}\text { Caplan et al.'s measure of work } \\
\text { dissatisfaction (1975) }\end{array}$ & 1 \\
\hline $\begin{array}{l}\text { Gray-Toft \& Anderson's measure of JS } \\
\text { (1985) }\end{array}$ & 1 \\
\hline Strumpfer \& Louw's measure of JS (1990) & 1 \\
\hline Harrison \& Pinneau's measure of JS (1975) & 1 \\
\hline $\begin{array}{l}\text { Global Job Satisfaction Index } \\
\text { (Quinn \& Shepard, 1974) }\end{array}$ & 1 \\
\hline $\begin{array}{l}\text { Minnesota Satisfaction Questionnaire } \\
\text { (Weiss, Dawis, England, \& Lofquist, 1967) }\end{array}$ & 1 \\
\hline Parkes' measure of JS (1993) & 1 \\
\hline $\begin{array}{l}\text { Job Content Questionnaire } \\
\text { (Karasek et al., 1985) }\end{array}$ & 1 \\
\hline McLean's measure of JS (1979) & 1 \\
\hline $\begin{array}{l}\text { Pressure Management Indicator } \\
\text { (Williams \& Cooper, 1998) }\end{array}$ & 1 \\
\hline
\end{tabular}


TABLE IV

Negative Affectivity Instruments

\begin{tabular}{|c|c|}
\hline SCALE & FREQUENCY \\
\hline $\begin{array}{l}\text { Center for Epidemiological Studies- } \\
\text { Depression (Radloff, 1977) }\end{array}$ & 4 \\
\hline $\begin{array}{l}\text { Taylor Manifest Anxiety Scale } \\
\text { (Taylor, 1953) }\end{array}$ & 3 \\
\hline $\begin{array}{l}\text { Positive and Negative Affectivity Scale } \\
\text { (Watson et al., 1988) }\end{array}$ & 3 \\
\hline $\begin{array}{l}\text { State-Trait Anxiety Inventory } \\
\text { (Spielberger, Gorsuch, \& Lushene, 1970) }\end{array}$ & 3 \\
\hline $\begin{array}{l}\text { Anxiety-Depression-Irritation Scale } \\
\text { (Caplan, 1975; Zung, 1965; Gurin et al., } \\
\text { 1960) }\end{array}$ & 3 \\
\hline $\begin{array}{l}\text { State-Trait Personality Inventory, Trait } \\
\text { Anxiety Scale (Spielberger, 1979) }\end{array}$ & 2 \\
\hline $\begin{array}{l}\text { Eysenck Personality Inventory } \\
\text { (Eysenck \& Eysenck, 1963) }\end{array}$ & 2 \\
\hline $\begin{array}{l}\text { Mental Health Battery } \\
\text { (Ware, Johnston, Davies-Avery, \&Brook, } \\
\text { 1979) }\end{array}$ & 2 \\
\hline $\begin{array}{l}\text { Multidimensional Personality } \\
\text { Questionnaire (Tellegen, 1982; Tellegen \& } \\
\text { Waller, 1992) }\end{array}$ & 2 \\
\hline $\begin{array}{l}\text { Crown-Crisp Experimental Index } \\
\text { (Crown \& Crisp, 1979) }\end{array}$ & 2 \\
\hline Quinn \& Shepard's measure of NA (1974) & 2 \\
\hline $\begin{array}{l}\text { Multidimensional Personality Index } \\
\text { (Agho, Mueller, \& Price, 1992) }\end{array}$ & 1 \\
\hline $\begin{array}{l}\text { Watson \& Tellegen's measure of NA } \\
\text { (1985) }\end{array}$ & 1 \\
\hline Braithwaite's measure of NA (1987) & 1 \\
\hline $\begin{array}{l}\text { Affect Adjective Checklist for Anxiety } \\
\text { (Zuckerman, 1960) }\end{array}$ & 1 \\
\hline Pines et al.'s measure of NA (1980) & 1 \\
\hline $\begin{array}{l}\text { Job Content Questionnaire (Karasek et al., } \\
\text { 1985) }\end{array}$ & 1 \\
\hline $\begin{array}{l}\text { Pressure Management Indicator } \\
\text { (Williams \& Cooper, 1998) }\end{array}$ & 1 \\
\hline
\end{tabular}


TABLE V

\section{Artifact Distributions}

\begin{tabular}{ll}
\hline Variable & Mean Square Root of Reliability \\
\hline Role Conflict & .8811 \\
Role Ambiguity & .8805 \\
Job Satisfaction & .9077 \\
Negative Affectivity & .9074 \\
Role Conflict * & .8810 \\
Jobs Satisfaction * & .9062 \\
Negative Affectivity * & .9074 \\
\hline
\end{tabular}

* The data from the Williams \& Cooper (1998) study were excluded when the mean square root of reliability was taken for these variables. 
TABLE VI

Meta-Analysis

\begin{tabular}{llllllll}
\hline Variables & $\mathrm{K}$ & $\mathrm{N}$ & $\mathrm{RBAR}$ & $\mathrm{SDr}$ & $\rho$ & $\mathrm{SD} \rho$ & $95 \% \mathrm{CI}$ \\
\hline RC-JS & 51 & 43625 & -.10 & .1156 & -.12 & .1363 & -.39 to .15 \\
RC-NA & 58 & 30938 & .27 & .0722 & .33 & .0704 & .19 to .47 \\
RC-RA & 27 & 6613 & .33 & .1209 & .42 & .1314 & .16 to .68 \\
RA-JS & 49 & 10152 & -.28 & .2520 & -.35 & .3000 & -.94 to .24 \\
RA-NA & 43 & 11184 & .21 & .1015 & .27 & .0997 & .07 to .47 \\
NA-JS & 82 & 37445 & -.28 & .1015 & -.34 & .1078 & -.55 to -.13 \\
RC-JS $*$ & 47 & 9613 & -.30 & .0978 & -.37 & .0874 & -.54 to -.20 \\
RC-NA $*$ & 56 & 13932 & .23 & .0891 & .29 & .0788 & .14 to .44 \\
NA-JS $*$ & 80 & 20439 & -.24 & .0162 & -.30 & .1215 & -.54 to -.06 \\
\hline
\end{tabular}

Note. $K$, number of correlations included in the analysis; $N$, total sample size; $R B A R$, sample size weighted mean observed correlation; $S D r$, sample size weighted standard deviation of mean observed correlation; $\rho$, RBAR corrected for unreliability; $S D \rho$, standard deviation of $\rho ; 95 \% C I, 95 \%$ credibility intervals, computed as $\rho+1.96$ SD $p$. * The data from the Williams \& Cooper (1998) study were excluded when conducting these meta-analyses. 


\section{LIST OF REFERENCES}

Abdalla, I. A. (1991). Social Support and Gender Responses to Job Stress in an Arab Culture. Journal of Social Behavior and Personality, 6 (7), 273-288.

Abramis, D. J. (1994). Work role ambiguity, job satisfaction, and job performance: Meta-analysis and review. Psychological Reports, 75, 1411-1433.

Agho, A. O., Mueller, C. W., \& Price, J. L. (1993). Determinants of Employee Job Satisfaction: An Empirical Test of a Causal Model. Human Relations, 46(8), 10071027.

Aiken, L., \& West, S. G. (1993). Detecting interactions in multiple regression: Measurement error, power, and design considerations. The Score, APA Division 5 Newsletter, 16, 7.

Beehr, T. A. (1996).Basic Organizational Psychology. Boston: Allyn and Bacon.

Beehr, T. A., \& McGrath, J. E. (1992). Social support, occupational stress and anxiety. Anxiety, Stress, and Coping, 5, 7-19.

Breaugh, J. A., \& Colihan, J. P. (1994). Measuring facets of job ambiguity: Construct validity evidence. Journal of Applied Psychology, 79(2), 191-202.

Brief, A. P., Burke, M.J., George, J.M., Robinson, B. S., \& Webster, J. (1988). Should negative affectivity remain an unmeasured variable in the study of job stress? Journal of Applied Psychology 73(2), 193-198.

Brown, S. P., \& Peterson, R. A. (1993). Antecedents and consequences of salesperson job satisfaction: Meta-analysis and assessment of causal effects. Journal of Marketing Research, 30, 63-77.

Butler, M. C. \& Ehrlich, S. B. (1991). Positional influences on job satisfaction and job performance: a multivariate, predictive approach. Psychological Reports, 69 , 855-865.

Chen, P.Y., \& Spector, P. E. (1991). Negative Affectivity as the Underlying Cause of Correlations Between Stressors and Strains. Journal of Applied Psychology, 76 (3), 398-407.

Clark, M.S., \& Isen, A. M. (1982). Toward understanding the relationship between feeling states and social behavior. In A. H. Hastorf \& A.M. Isen (Eds.), Cognitive social psychology (pp. 73-108). New York: Elsivier. 
Cordes, C. L., \& Dougherty, T. W. (1993). A review and an integration of research on job burnout. Academy of Management Review, 18, 621-656.

Fisher, C. D., \& Gitelson, R. (1983). A meta-analysis of the correlations of role conflict and ambiguity. Journal of Applied Psychology, 68, 320-333.

Fulk, J., \& Wendler, E. R. (1982). Dimensionality of leader-subordinate interactions: A path-goal investigation. Organizational Behavior and Human Performance, $30,241-264$.

Ganster, D. C., Fusilier, M. R., \& Mayes, B.T. (1986). Role of social support in the experience of stress at work. Journal of Applied Psychology, 71, 102-110.

George, J. M. (1996). Trait and state affect. In K.R. Murphy (Ed.), Individual differences and behavior in organizations (pp. 145-171). San Francisco: Jossly- Bass.

Hackman, J. R., \& Oldham, G. R. (1976). Motivation through the design of work: Test of a theory. Organizational Behavior and Human Performance, 16, 250-279.

Hackman, J. R., \& Oldham, G. R. (1980). Work Redesign. Reading, MA: Addison-Wesley.

Heinisch, D. A., \& Jex, S. M. (1997). Negative affectivity and gender as moderators of the relationship between work-related stressors and depressed mood at work. Work \& Stress, 11(1), 46-57.

Hom, P. W., Caranikas-Walker, F., Prussia, G. E, \& Griffeth, R.W. (1992). A meta-analytical structural equations analysis of a model of employee turnover. Journal of Applied Psychology, 77(6), 890-909.

Hunter, J. E., \& Schmidt, F. L. (1990). Methods of meta-analysis: Correcting for error and bias in research findings. Newbury Park, CA: Sage.

Jackson, S. E., \& Schuler, R. S. (1985). A meta-analysis and conceptual critique of research on role ambiguity and role conflict in work settings. Organizational Behavior and Human Decision Processes, 36, 16-78.

Kahn, R. L. (1973). Conflict, ambiguity, and overload: Three elements in job stress. Occupational Mental Health, 3, 2-9.

Kahn, R.L., Wolfe, D. M., Quinn, R. P., Snoek, J. D., \& Rosenthal, R.A. (1964). Organizational Stress: Studies in role conflict and role ambiguity. New York: Wiley. 
Kemery, E. R. (1991). Affective disposition, role stress, and job withdrawal. Journal of Social Behavior and Personality, 6(7), 331-347.

Kim, S. W., Price, J.L., Mueller, C. W., \& Watson. T.W. (1996). The determinants of career intent among physicians at a U.S. air force hospital. $\underline{\text { Human }}$ Relations, 49(7), 947-976.

King, L. A., \& King, D. W. (1990). Role conflict and role ambiguity: A critical assessment of construct validity. Psychological Bulletin, 107(1), 48-64.

Locke, E. A. (1976). The nature and causes of job satisfaction. In M.D. Dunnette (Ed.), Handbook of industrial and organizational psychology. Chicago: Rand McNally.

Netemeyer, R.G., Johnston, M.W., \& Burton, S. (1990). Analysis of role conflict and role ambiguity in a structural equations framework. Journal of Applied Psychology, $75,148-157$.

Nhundu, T. J. (1992). Job performance, role clarity, and satisfaction among teacher interns in the Edmonton public school system. The Alberta Journal of Educational Research, 38 (4), 335-354.

Sanchez, J.I., \& Viswesvaran, C. (1996, April). An assessment of spuriousness in the cross-sectional relations among self-reported stressors and strains. Poster presented at the $11^{\text {th }}$ annual meeting of the Society for Industrial and Organizational Psychology, San Diego, CA.

Sawyer, J. E. (1992). Goal and process clarity: Specification of multiple constructs of role ambiguity and a structural equation model of their antecedents and consequences. Journal of Applied Psychology, 77 (2), 130-142.

Schmidt, F. L., Law, K., Hunter, J. E., Rothstein, H. R., Pearlman, K., McDaniel, M. (1993). Refinements in validity generalization methods: Implications for the situational specificity hypothesis. Journal of Applied Psychology, 78, 3-12.

Singh, J., Goolsby, J. R., \& Rhoads, G. K. (1994). Behavioral and Psychological Consequences of Boundary Spanning Burnout for Customer Service Representatives. Journal of Marketing Research, 31, 558-569.

Szilagyi, A. (1977). An empirical test of causal inference between role perceptions, satisfaction with work, performance and organizational level. Personnel Psychology, 30, 375-387.

Viswesvaran, C., \& Ones, D. S. (1995). Theory testing: Combining psychometric meta-analysis and structural equations modeling. Personnel Psychology, 48(4), 865-885. 
Viswesvaran, C., Sanchez, J. I., \& Fisher, J. (1999). The role of social support in the process of work stress: A meta-analysis. Journal of Vocational Behavior, 54, 314334.

Vroom, V. H. Work and motivation. (1964). New York: Wiley.

Watson, D., \& Clark, L.A. (1984). Negative affectivity: The disposition to experience aversive emotional states. Psychological Bulletin, 96, 465-490.

Watson, D., Clark, L. A., \& Tellegen, A. (1988). Development and validation of brief measures of positive and negative affect: The PANAS scales. Journal of Personality and Social Psychology, 54, 1063-1070. 


\section{APPENDIX}

\section{Studies Included in Meta-Analysis}

Abramis, D. J. (1994). Relationships of job stressors to job performance: Linear or an inverted-U? Psychological Reports, 75, 547-558.

Agho, A. O., Mueller, C. W., \& Price, J. L. (1993). Determinants of Employee Job Satisfaction: An Empirical Test of a Causal Model. Human Relations, 46(8), 10071027.

Axelrod, W. L., \& Gavin, J. F. (1980). Stress and Strain in Blue-Collar and White-Collar Management Staff. Journal of Vocational Behavior, 17, 41-49.

Barling, J, \& Macewen, K. E. (1992). Linking work experiences to facets of marital functioning. Journal of Organizational Behavior, 13 , 573-583.

Beatty, C. A. (1996). The stress of managerial and professional women: is the price too high? Journal of Organizational Behavior, 17, 233-251.

Beehr, T. A. (1976). Perceived Situational Moderators of the Relationship Between Subjective Role Ambiguity and Role Strain. Journal of Applied Psychology, 61(1), 35-40.

Beehr, T. A., King, L. A., \& King, D. W. (1990). Social Support and Occupational Stress: Talking to Supervisors. Journal of Vocational Behavior, 36, 61-81.

Cassar, V., \& Tattersall, A. (1998) Occupational stress and negative affectivity in Maltese nurses: testing moderating influences. Work \& Stress, 12(1), 85-94.

Chen, P. Y., \& Spector, P. E. (1991). Negative Affectivity as the Underlying Cause of Correlations Between Stressors and Strains. Journal of Applied Psychology, 76(3), 398-407.

Cooper, C. L., \& Mitchell, S. (1990). Nursing the Critically Ill and Dying. Human Relations, 43(4), 297-311.

Decker, P. J., \& Borgen, F. H. (1993). Dimensions of Work Appraisal: Stress, Strain, Coping, Job Satisfaction, and Negative Affectivity. Journal of Counseling Psychology, 40 (4), 470-478.

Dollard, M. F., \& Winefield, A. H. (1998). A Test of the DemandControl/Support Model of Work Stress in Correctional Officers. Journal of Occupational Health Psychology, 3(3), 243-264. 
Edwards, J. R., \& Van Harrison, R. (1993). Job Demands and Worker Health: Three-Dimensional Reexamination of the Relationship Between Person-Environment Fit and Strain. Journal of Applied Psychology, 78(4), 628-648.

Endreden, I. M., Vaernes, R., Ursin, H., \& Tonder, O. (1987). Psychological stress-factors and concentration of immunoglobulins and complement components in Norwegian nurses. Work \& Stress, 1(4), 365-375.

Frone, M. R. (1998). Predictors of Work Injuries Among Employed Adolescents. Journal of Applied Psychology, 83(4), 565-576.

Ganster, D. C., Fusilier, M. R., \& Mayes, B. T. (1986). Role of Social Support in the Experience of Stress at Work. Journal of Applied Psychology, 71 (1), 102-110.

Gavin, J. F., \& Axelrod, W. L. (1977). Managerial Stress and Strain in a Mining Organization. Journal of Vocational Behavior, 11, 66-74.

Iverson, R. D., \& Kuruvilla, S. (1995). Antecedents of union loyalty: the influence of individual dispositions and organizational context. Journal of Organizational Behavior, 16, 557-582.

Iverson, R. D., Olekalns, M., Erwin, P. J. (1998), Affectivity, Organizational Stressors, and Absenteeism: A Causal Model of Burnout and Its Consequences. Journal of Vocational Behavior, 52, 1-23.

Iwata, N., Suzuki, K, Saito, K., \& Abe, K. (1992). Type A Personality, Work Stress, and Psychological Distress in Japanese Adult Employees. Stress Medicine, 8, 1121.

Jex, S. M., Beehr, T. A., \& Roberts, C. K. (1992). The Meaning of Occupational Stress Items to Survey Respondents. Journal of Applied Psychology, 77(5), 623-638.

Jex, S. M., \& Spector, P. E. (1996). The impact of negative affectivity on stressor-strain relations: a replication and extension. Work \& Stress, 10 (1), 36-45.

Kemery, E. R. (1991). Affective Disposition, Role Stress, and Job Withdrawal. Journal of Social Behavior and Personality, 6 (7), 331-347.

Kim, S. W., Price, J. L., Mueller, C.W., \& Watson, T. W. (1996). The Determinants of Career Intent Among Physicians at a U.S. Air Force Hospital, Human Relations, 49(7), 947-976.

Landsbergis, P. A., \& Vivona-Vaughan, E. (1995). Evaluation of an occupational stress intervention in a public agency. Journal of Organizational Behavior, 16, 29-48. 
Moss, S. E., \& Lawrence, K. G. (1997). The effects of priming on the selfreporting of perceived stressors and strains. Journal of Organizational Behavior, 18, 393403.

Moyle, P. (1998). Longitudinal influences of managerial support on employee well-being. Work \& Stress, 12(1) 29-49.

Parasuraman, S., \& Alutto, J. A. (1984). Sources and Outcomes of Stress in Organizational Settings: Toward the Development of a Structural Model. Academy of Management Journal, 27 (2), 330-350.

Parasuraman, S., \& Cleek, M. A. (1984). Coping Behaviors and Managers' Affective Reactions to Role Stressors. Journal of Vocational Behavior, 24, 179-193.

Revicki, D. A., Whitley, T. W., \& Gallery, M. E. (1993). Organizational Characteristics, Perceived Work Stress, and Depression in Emergency Medicine Residents. Behavioral Medicine, 19, 74-81.

Schaubroeck, J., Ganster, D. C., \& Fox, M. L. (1992). Dispositional Affect and Work-Related Stress. Journal of Applied Psychology, 77(3), 322-335.

Schaubroeck, J., Ganster, D. C., Sime, W. E., \& Ditman, D. (1993). A field experiment testing supervisory role clarification. Personnel Psychology, 46, 1-25.

Schaubroeck, J., Judge, T. A., Taylor III, L. A. (1998). Influences of Trait Negative Affect and Situational Similarity on Correlation and Convergence of Work Attitudes and Job Stress Perceptions Across Two Jobs. Journal of Management, 24, (4), 553-576.

Shamir, B., \& Drory, A. (1981). A study of cross-cultural differences in work attitudes among three groups of Israeli prison employees. Journal of Occupational Behaviour, 2, 267-282.

Stewart, W., \& Barling, J. (1996). Daily work stress, mood and interpersonal job performance: a mediational model. Work \& Stress, 10(4), 336-351.

Strumpfer, D. J. W. (1997). The relation between religious motivation and workrelated variables amongst agricultural workers. South African Journal of Psychology, 27(3), 134-142.

Sutherland, V., \& Davidson, M. J. (1993). Using a stress audit: the construction site manager experience in the UK. Work \& Stress, 7(3), 273-286. 
Terry, D. J., Nielsen, M., \& Perchard, L. (1993). Effects of Work Stress on Psychological Well-Being and Job Satisfaction: The Stress- Buffering Role of Social Support. Australian Journal of Psychology, 45(3), 168-175.

Thomas, L. T., \& Ganster, D. C. (1995). Impact of Family-Supportive Work Variables on Work- Family Conflict and Strain: A Control Perspective. Journal of Applied Psychology, 80(1), 6-15.

Williams, K. J., Suls, J., Alliger, G. M., Learner, S. M., Wan, C. K. (1991). Multiple Role Juggling and Daily Mood States in Working Mothers: An Experience Sampling Study. Journal of Applied Psychology, 76 (5), 664-674.

Williams, L. J., Gavin, M. B., \& Williams, M. L. (1996). Measurement and Nonmeasurement Process With Negative Affectivity and Employee Attitudes. Journal of Applied Psychology, 81(1), 88-101.

Williams, S., \& Cooper, C. L. (1998). Measuring Occupational Stress: Development of the Pressure Management Indicator. Journal of Occupational Health Psychology, 3(4), 306-321. 